\title{
МЕТОДОЛОГИЧЕСКИЙ КРИЗИС РОССИЙСКОГО ФЕДЕРАЛИЗМА
}

\begin{abstract}
Аннотация: B статье рассматриваются конституцуионно-правовые и политические трансфор-мации последних лет, последовательное внедрение идей конституционализма в россий-скую теорию и практику, выстраивание новой модели федеративных отношений порой на фоне отсутствия концептуального понимания происходящих процессов и явлений, ко-торые актуализируют проблему методологического исследования современного россий-ского федерализма. Автором рассматривается и теоретическая проблема российского федерализма - сочетаемость принциипов: с одной сторонь - иентрализма, а с другой - децентрализма, как новой национальной формы демократии, дающей сбои и испьть-вающей пока отторжение у части управленческого класса и у общества.

Ключевые слова: Юриспруденция, Федерация, Федерализм, Централизация, Децентрализация, Субъектность, Политический регион, Политическая элита, Федеративные интересы, Федеративные процессы
\end{abstract}

$\mathrm{H}$ есмотря на постепенное вытеснение проблематики федеративных отношений из публичного дискурса и замещение самого понятия «федерализм» иными речевыми практиками - такими, как «государственное строительство» и «региональное управление», острота проблемы взаимоотношений Центра и регионов в последнее время стала ещё более очевидной, а интенсивность процессов межэлитных взаимодействий в различных сферах региональной политики заметно возросла.

Сегодня опыт федерализма в России требует обстоятельного многостороннего анализа как с точки зрения выявления общей логики его институционального развития, так и с точки зрения рассмотрения основных противоречий, присущих федеративной системе на настоящем этапе. За последние двадцать лет российская политическая система прошла через сложный период адаптации федеративных институтов, включивший в себя как процесс конституционно-правового закрепления принципов федерализма, так и «освоения» центральной и региональной элитой новых формальных институтов федеративного устройства в качестве правил игры. В этих условиях внимание исследователей было в основном обращено либо к анализу структурных особенностей федерализма и проблеме формирования его наиболее адекватной модели для России, либо к анализу изменений различных конфигураций правил игры в рамках федеративной системы, обусловленных взаимодействием элитных групп Центра и регионов.
В настоящей ситуации особенно важным становится выявление общих закономерностей и анализ динамики развития российского федерализма, которые позволяют понять как условия формирования системы «нового централизма», так и условия её воспроизводства и постепенной трансформации.

Очевидно, что функционирование системы взаимодействий Центра и регионов в России оказывается всё менее зависимо от субъектного фактора. Возрастающий элемент неопределённости, случайность принимаемых решений и стихийный характер воспроизводства целого ряда управленческих механизмов становится трудно объяснить выбором стратегий и изменениями правил игры. Все эти факторы постепенно приобретают отчётливый характер системного свойства, выступая следствием глубоких противоречий, имеющих место внутри институционального комплекса федеративной системы. При этом в большинстве случаев эти противоречия существуют не между формальными нормами и неформальными практиками, а укореняются внутри самих неформальных практик. В современных условиях неформальные механизмы взаимодействия Центра и регионов из временного явления и своего рода побочного эффекта межэлитного сотрудничества превратились в функциональный инвариант развития федеративной системы. Кроме того, они оказываются тесно переплетены с практиками, сложившимися в рамках системы административного управления, внутрипартийного сотрудничества, электоральной политики. 


\section{Политика и общество 1 (97) 2013}

Как следствие, сегодня проблематика федерализма всё в большей степени определяется не выбором оптимальной модели государственно-территориального устройства и не ситуативным использованием федеративных институтов элитами Центра и регионов, а характером его встроенности в сложившийся порядок политических взаимодействий. Поэтому на настоящем этапе важное значение приобретает теоретический анализ особенностей развития российской федеративной системы и, прежде всего, различных форм существования институтов федерализма, ключевых механизмов, способствующих их воспроизводству, а также того эффекта, который эти институты в состоянии оказывать на поведение основных акторов политической системы.

В современных условиях исследования федерализма характеризует доминирование двух основных традиций его изучения, предлагающих два фундаментально различных понимания его природы, сущности и форм.

Первая традиция опирается преимущественно на формально-правовые, структурно-функционалистские и нормативно-ценностные концепции и может быть обозначена как «объективистская». В её рамках федерализм предстаёт совокупностью устойчивых принципов, определяемых набором универсалий конституционно-правовых норм, социально-культурных характеристик или политических ценностей. Вне зависимости от того, какой именно набор универсалий оказывается в фокусе исследовательского внимания, федерализм в данном методологическом ракурсе всегда имеет чёткие системные границы и принципы, а складывающееся на их основе федеративное устройство рассматривается как самодостаточный и самоценный феномен.

Вторая традиция основывается на принципах методологического индивидуализма и может быть обозначена как «субъективистская». В рамках этой традиции федерализм фактически лишён системных свойств и выступает ситуативным феноменом, проявляющимся в самом взаимодействии политических акторов. Концентрированным выражением «субъективистского» понимания федерализма выступает его инструменталистская трактовка, реконструкция концептуальных границ которой позволяет выявить два фундаментальных методологических принципа рассмотрения федерализма в данном ракурсе: во-первых, как средства и механизма достижения политических целей, вовторых, как временного явления, предполагающего возможность существования чётких временных границ федеративного проекта.

Глубокое противоречие между двумя традициями, утвердившееся в научной практике, позволяет говорить о том, что современное состояние федералистских исследований характеризуется ситуацией дуализма. Этот дуализм обуславливается не просто существованием двух традиций анализа, подчёркивающих разные стороны и аспекты федеративных отношений, но существованием двух противоположных практик изучения федерализма, которые опираются на взаимоисключающие методологические принципы и ориентированы на объяснение одних и тех же процессов и явлений.

Побочным эффектом такой ситуации является то, что на фоне противопоставления двух доминирующих исследовательских традиций вне ракурса рассмотрения оказывается множество иных форм и проявлений федеративных отношений, анализ которых не вписывается в устоявшиеся концептуальные схемы. В этом смысле, преодоление сложившегося дуализма обуславливается естественной необходимостью объяснения тех тенденций и процессов, характеризующих развитие современных федеративных государств, которые либо не получают достаточного объяснения в рамках «объективистской» и «субъективистской» традиций, либо в принципе выпадают из их исследовательского фокуса.

Очевидно, что в методологическом плане это преодоление не может быть связано с простым искусственным синтезом принципов и установок, присущих обеим исследовательским традициям. Альтернативный ракурс рассмотрения федеративных отношений должен опираться на самостоятельные концептуальные основания, учитывая теоретико-методологический потенциал, накопленный современной политической наукой, а также применяемые в её рамках новые исследовательские инструменты. Но, самое главное, любые новые подходы и концепции должны быть соразмерны и адекватны самому предмету анализа, т.е. тем процессам и явлениям в сфере развития федеративных отношений, которые требуют более глубокого изучения.

Таким образом, ситуация доминирования двух основных исследовательских традиций, характеризующая сегодняшнее состояние федералистских исследований, заставляет обращаться к рассмотрению предпосылок, обуславливающих необходимость использования нового теоретического ракурса в изу- 
чении современного опыта федерализма как в теоретическом плане, так и в плане изменений в самой политической практике федеративных государств.

В настоящее время развитие федеративных отношений характеризует ряд тенденций, при объяснении которых утвердившиеся подходы и концепции испытывают серьёзные трудности. Эти тенденции связаны не столько с новыми проявлениями и сферами распространения федерализма, сколько с новыми формами его существования.

Во-первых, утверждение федеративных структур и институтов сегодня всё в большей степени приобретает фрагментарный характер, что, в частности, проявляется в распространении практик децентрализованного управления и адаптации отдельных принципов федерализма в различных вариациях в «усечённом» виде, вне целостной системы федеративного устройства.

Во-вторых, характер и динамика развития федеративной системы оказываются всё более зависимы от социального контекста, а именно - от конкретной институциональной среды, в которую помещаются федеративные институты. Процесс федерализации и распространения многоуровневой системы управления ведёт не столько к закреплению и утверждению универсального набора федеративных институтов, сколько к различным вариантам их интерпретации в зависимости от конкретных социальных условий. Как следствие, в каждом случае складывается особая конфигурация институтов и практик федерализма, встроенных в общий контекст политических взаимодействий того или иного общества.

Наконец, в-третьих, одним из определяющих факторов развития федеративной системы становятся утверждающиеся в её границах неформальные механизмы согласования интересов между политическими акторами. При этом из ситуативного явления и временной девиации они превращаются в функциональный инвариант развития системы отношений Центра и регионов, по-разному проявляясь как в новых, развивающихся, федеративных государствах, так и в классических федерациях.

Стоит заметить, что теоретическая реконструкция взглядов авторов классических работ по теории федерализма - в частности, К.Уира, У. Ливингстона, У. Райкера и К.Фридриха - показывает, что проблема соотношения федеративных структур со сложившимися в обществе практиками взаимодействия выступала одной из ключевых в общих рассуждениях исследователей, вне зависимости от методологического контекста анализа.
Такие тенденции отчётливо демонстрируют, что значимость федерализма в современных условиях всё в большей степени определяется не структурным аспектом (конституционно-правовые нормы, система органов управления) или стратегическим аспектом (деятельность основных политических акторов - элитных групп Центра и регионов), а теми формами устойчивых взаимоотношений, которые он приобретает, будучи встроенным в сложившийся в обществе порядок политических взаимодействий. Как следствие, ключевая проблема федералистских исследований в данном ракурсе может быть сформулирована следующим образом: как федеративные структуры встраиваются в сложившийся в обществе порядок взаимодействий политических акторов.

Если предположить, что федерализм имеет «структурирующее» воздействие на процесс взаимодействия политических акторов, то оно заключается в том, что федеративные структуры в состоянии формировать определённые модели поведения политических акторов, воспроизводимые впоследствии в практиках их взаимодействий. В этом случае, основным предметом изучения должны стать сами факторы, обеспечивающие устойчивость воспроизводства федеративных отношений, а именно - устойчивые практики взаимодействия, утверждающиеся в рамках федеративной системы, которые, с одной стороны, складываются на основе закреплённых формальных структур, с другой - воспроизводятся в непрерывных взаимодействиях политических акторов. Особое значение в этом случае приобретает анализ условий, механизмов, а также степени устойчивости их воспроизводства.

Стоит подчеркнуть, что федерализм - сам по себе, как феномен - теоретически, концептуально и конституционно материализованная реальность - сложное явление. Может быть, поэтому федерализм всегда анализировался по множеству направлений. Исследователь Н.В. Михайлова обоснованно пишет: «Современный федерализм - явление сложное и неоднозначное. Это не застывшая модель, которую можно прикладывать к различным обществам и ситуациям. Это постоянный поиск новых, не стандартных решений. Сама концепция федерализма непрестанно эволюционирует». В развитие своей мысли ею выделяется пять «основ» «Типичного возникновения классического федеративного государства: снизу - вверх, от малого - к большому, от множества - к единому» ${ }^{1}$. В суждени-

\footnotetext{
${ }^{1}$ См.: Михайлова Н.В. Политологический анализ сущности понятия «федерализм» и «федерация» / В кн. Актуальные вопросы политической науки. Сборник статей российских и зарубежных ученых. М., 2010. С. 143.
} 


\section{Политика и общество 1 (97) • 2013}

ях и доводах Н.В. Михайловой очень важно подчеркнуть ту особенность процесса формирования федеративного государства, которая связана с типичной логикой государствообразующего федеративного процесса. Вектор направленности очевиден: снизу - вверх. Возможно, здесь преувеличены роль и значение низовых субъектов политики вообще, и в территориально-государственном обустройстве, в частности. Тем не мене, следует такую парадигму образования федеративного государства действительно признавать не только универсальной, но и в определенном смысле закономерной. Конечно, такая логика - это вопрос не столько с неоднозначным решением, сколько предпочтением «вкусов» и убеждений самого исследователя. Чему отдать предпочтение, - стихии народного созидательного творчества, ее какой-то форме все же организации, либо целеустремленной и спланированной акции наиболее активной части политической элиты. Если все же придерживаемся убеждений, что энергия универсальности и закономерностей в государственно образующем процессе имеет право быть и утверждаться, тогда столь же закономерным и универсальным явлением в таком случае следует рассматривать инициирующую роль местных и региональных структур власти, которые, собственно, призваны задавать тональность созидания «снизу». В таком контексте речь может идти ни о чем другом, как собственно о проявлениях различного рода правовой субъектности региональных и местных структур власти и гражданского общества.

Коррелируется с такого рода суждениями известный регионалист Р.Ф. Туровский, который утверждает: «Под территориально-государственным строительством понимается процесс направленного формирования отношений между центром и регионами» ${ }^{2}$. Направленное формирование процесса - очевидно, и это ключевой аспект в системе наших рассуждений. Всякий, кто причастен к этому процессу, поступает все же с определенной целью, задачами и прочими атрибутами рационального подхода. Если к этому процессу причастны региональные и местные структуры, то и они запрограммированы действовать в русле направленного действия. Здесь важно иметь в виду два соображения. Первое - участвуют ли региональные и местные власти в процессе направленного действия? По мнению Р.Ф. Туровского, - да.

По мнению исследователя, субъектами процесса территориально-государственного строительства яв-

${ }^{2}$ См.: Туровский Р.Ф. Политическая регионалистика. М., 2006. C. 69. ляются все властные органы непосредственно, а также иные политические институты и группы, которые обычно действуют опосредованно, пытаясь влиять на властные органы. Второе - направленное действие суть движений (мыслительных, рефлексирующих и прочих) субъекта этого действия. Но одновременно направленное действие может быть продуктом другого субъекта, задающего параметры действий непосредственному исполнителю действий. В структуре баланса отношений и соотношений центр - регион, выделение и анализ направленного действия имеет существенное значение. В нашем случае, т.е. анализе феномена субъектности региональной и местной власти - это существенный элемент.

Это общие рассуждения, но, надо понимать, общих рассуждений здесь недостаточно. Характер, масштаб, форма, механизмы участия властных структур отдельных частей государства не имеют принципиального значения, чтобы характеризовать деятельность властных структур по признакам федеративного устройства. Процедурно-техническая сторона этого дела существенна, но не абсолютна. Абсолютное значение для подтверждения уровня федерализации имеет сам факт участия власти регионов и мест в делах общенационального значения. «Мы называем федеративным такое государство, отдельные части которого являются участниками в отправлении верховной государственной власти или суверенитета»³.

Чтобы усилить логику нашего видения проблемы самого факта участия региональных и местных органов власти в делах общефедерального и общенационального уровня, сошлемся на суждение известного исследователя Г. Еллинека, который пишет, что в федеративном государстве «государствам предоставлены права участия в осуществлении союзной государственной власти, так что отдельные государства повсюду являются органами союзной власти, что, по общему правилу, усиливает их политическое значение».

В условиях развития федеративных отношений в современной России выделение проблемы интереса актуально и требует адекватного его прояснения. Как понимается и интерпретируется эта проблема? Например, исследователь Ю.Б. Дмитриева описывает эту проблему следующим образом. С ее точки зрения, во-первых, наибольшую значимость обретают общенациональные стратегии социально-экономического

\footnotetext{
${ }^{3}$ См.: Алексеев Н.Н. Советский федерализм // В кн. Мир Россия - Евразия. Антология. М., 1995. С. 163.
} 
Государство и гражданское общество

и политического развития, учитывающие региональные интересы. Во-вторых, задача регионов состоит в более четком определении и конкретизации своих интересов, в продвижении и защите своих интересов на федеральном уровне с помощью формальных институтов и неформальных практик ${ }^{4}$. В такой интерпретации есть вполне здравый смысл. Он позволяет именно субъектам регионов дифференцированно подходить к выявлению и отстаиванию своих (региональных) интересов. Это норма административно-политической практики. Нормой административной практики может считаться выявление и отстаивание интереса общенационального. В какой мере субъекты регионов могут и способны участвовать в деле выражения интересов общенациональных, в такой мере можно говорить о качественных параметрах их субъектности.

Учёные часто говорят о субъектах политики, имея в виду государство, политические партии, политических лидеров, элиты. Модным стало говорить о различных группах интересов, давления, представительства. В модели федеративного обустройства можно наблюдать в качестве субъектов политики все вышеперечисленные категории политического действия. Из этого числа субъектов выпал народ. И если включить и его в число субъектов политики, то это будет формально и юридически верно, соответствовать конституционной норме. Но подобная логика почти никак не выражает потенциального и возможного значения граждан как субъектов политики. С нашей точки зрения, следует обратить внимание не только на граждан общества, как субъектов политики, а более всего на такую его характеристику, как «объединенная сила граждан».

Признание значения объединенной силы общества в качестве атрибута субъектности не снимает вопроса о том, на какой основе и что обеспечивает эту саму «объединенную силу», что ее формирует и превращает в силу единения и объединения частей, а не разлада и распада. Федерализм к этим тенденциям, как известно, чувствителен.

Пролонгация анализа теории федерализма - это возможность реконструкции применения базовых или отдельных рационалистических (даже прагматических) положений теории федерализма в полито-

\footnotetext{
${ }^{4}$ См.: Дмитриева Ю.Б. Отношения между центром и регионами в России: проблема эффективности // В кн. Теория и практика государственного и муниципального управления. Смоленск, 2010. С. 225, 226.
}

логической и политической практике в Российской Федерации. Если опираться все же на рационалистически-прагматические положения теории федерализма, то вряд ли будет достаточной и обоснованной мысль в рамках «нового федерализма» о необходимости возвращения субъектам Российской Федерации полномочий, присвоенных федеральным центром. На первый взгляд такая логика рассуждений на руку аналитикам в расшифровке субъектности региональной власти. Чего тут сложного в обретении субъектности - добились причитавшихся полномочий, и делу конец. Таким упрощенным путем решается проблема самоутверждения региональной власти, т.е. ее хотя бы частичная субъектность.

Создаются условия и возможности воплощения эффективной, действенной и целостной системы многоступенчатого властвования и управления. Это реакция на современность в федеративных отношениях, которая характеризуется параллельным существованием двух взаимоисключающих процессов: во-первых, некоторым повышением потенциала федерализма, прослеживаемым преимущественно со стороны субъектов Российской Федерации и выразившимся в стремлении региональных элит к установлению максимально сбалансированных отношений с федеральным центром. Главным здесь был бы учтен весь комплекс местных проблем и потребностей. Данная тенденция отражается, в частности, и в инициировании лидерами республик в составе Российской Федерации и главами городских, областных и краевых администраций новых законоположений по юридическому оформлению и закреплению статуса отдельно взятого региона в обновляющейся системе федеративных отношений России, процесс конституирования которых, по сути, приобрел новое качество. С другой стороны, и это, вовторых, выделяются, улавливаются, вбрасываются в информационное пространство суждения, свидетельствующие о будто бы проявляющейся крайне опасной для федеративного развития тенденций - унитаристской централизации, принижающей роль региональных и местных органов в общеполитических акциях.

Как актуализировать проблему потенциальных возможностей субъектности регионов в условиях, когда регионы, по мнению ряда исследователей, «лишились институциональных каналов представительства интересов», когда «отношения федерации и регионов стали более напряженными», но не привели к появлению региональной фронды, и региональные руководители выведены из большой политики? Достаточно ли 


\section{Политика и общество 1 (97) • 2013}

здесь оснований для такой интерпретации значения политической субъектности региональной и местной власти, если обратиться не столько к формальным фактам, сколько к содержанию и смыслам, отражаемым как в сообщениях о повседневных буднях текущей политической жизни, так и в аналитике и экспертизе «взглядов на политику федерального центра «из регионов»...»? Не факт, что достаточно. И тем не менее.

Концептуализация проблемы в балансе отношений «центр -регионы» в формате оценок политики федерального центра региональной властью, как можно видеть, является традиционным подходом исследователей российского федерализма и политической регионалистики. В данном случае мы используем концептуальный подход на заданную проблему известного ученого Н. Лапиной в работе «Отношения «центр - регионы» в современной России: пределы централизации».

Подводя итог, можно еще раз отметить, что федерализм представляет собой особый социальный и правовой порядок - особую власть, которую организует в пределах сложной территории федеративного государства. Кроме того, он придает власти свойства оптимальной функционирующей системы благодаря распределению по сформированным властным уровням конкретных властных полномочий. Управление осуществляется посредством сочетания принципов централизации и децентрализации, взаимной ответственности членов Федерации и федерального центра за реализацию очерченного для каждого уровня власти объема полномочий. Федерализм приобретает доминирующее положение в разрешении социально-экономических проблем государства в целом и членов федеративного образования. Для функционирования федерализма очень важно сочетание централизованных и децентрализованных методов управления, сохраняющих федерализм в его теории и практике и препятствующих его фрагментарной реализации. Федерализм предполагает развитие самодостаточности субъектов Федерации, поэтому наличие у них ресурсов власти является обязательным условием для увеличения имеющейся своей собственности, денежных ресурсов, привлечения инвестиций, своего политического и духовного потенциалов.

\section{Библиография:}

1. Алексеев Н.Н. Советский федерализм // В кн. Мир Россия - Евразия. Антология. М., 1995.

2. Бекбосынов М.Б. Проблемы оптимизации федеративных отношений в современной России. М., 2006.

3. Дмитриева Ю.Б. Отношения между центром и регионами в России: проблема эффективности // В кн. Теория и практика государственного и муниципального управления. Смоленск, 2010.

4. Михайлова Н.В. Политологический анализ сущности понятия «федерализм» и «федерация»/ В кн. Актуальные вопросы политической науки. Сборник статей российских и зарубежных ученых. М., 2010.

5. Туровский Р.Ф. Политическая регионалистика. M., 2006.

\section{References (transliteration):}

1. Alekseev N.N. Sovetskiy federalizm // V kn. Mir Rossiya - Evraziya. Antologiya. M., 1995.

2. Bekbosynov M.B. Problemy optimizatsii federativnykh otnosheniy v sovremennoy Rossii. M., 2006.

3. Dmitrieva Yu.B. Otnosheniya mezhdu tsentrom i regionami v Rossii: problema effektivnosti // V kn. Teoriya i praktika gosudarstvennogo i munitsipal'nogo upravleniya. Smolensk, 2010.

4. Mikhaylova N.V. Politologicheskiy analiz sushchnosti ponyatiya «federalizm» $\mathrm{i}$ «federatsiya» / V kn. Aktual'nye voprosy politicheskoy nauki. Sbornik statey rossiyskikh i zarubezhnykh uchenykh. M., 2010.

5. Turovskiy R.F. Politicheskaya regionalistika. M., 2006. 